\title{
History, extensive characterization and challenge of anti-tetanus serum from World War I: exciting remnants and deceived hopes
}

\section{Centenarian IgGs lost their neutralization capacity}

\author{
Nicolas Aubert ${ }^{1}$ - Marie Brachet-Botineau ${ }^{2}$ - Giulia Emi de Olivera Preto ${ }^{3} \cdot$ Isabelle Benz-de Bretagne $^{4,5}$. \\ Hervé Watier ${ }^{1,6}$. Guillaume Brachet ${ }^{1,6}$
}

Published online: 6 March 2020

(C) The Author(s) 2020

\begin{abstract}
During World War I (WWI), infectious diseases including tetanus were among the most important causes of death. Even though its efficacy was somewhat controversial before the war, tetanus antiserum played a key role in reducing the mortality of this disease. A vial of tetanus antiserum dating back from WWI, left behind on the French battlefield by the US Army, was borrowed from a private collection and opened. The serum contained within was characterized by orthogonal biochemical techniques to determine if any neutralizing IgGs could remain after 100 years of storage. In vitro analysis by Size Exclusion Chromatography and Serum Protein Electrophoresis suggested the presence of residual IgG. In spite of our hopes, these IgGs were not able to protect mice against tetanus toxin challenge in a neutralizing assay. Even though our results indicate the presence of remaining IgGs inside the serum, they were functionally disabled. These results show that obscurity alone is insufficient to protect IgGs from degradation over very long periods of time at room temperature.
\end{abstract}

\section{Highlights}

- Tetanus antiserum found its place in the therapeutic arsenal during World War I

- A century-old vial of tetanus antiserum was opened for biochemical and in vivo characterization

- Biochemical assays revealed the presence of proteins having all the characteristics of IgGs

- The serum was unable to protect mice against toxinic challenge

Keywords Antiserum $\cdot$ Tetanus $\cdot \operatorname{IgG} \cdot$ Stability $\cdot$ World War I

Electronic supplementary material The online version of this article (https://doi.org/10.1007/s12026-020-09121-z) contains supplementary material, which is available to authorized users.

Guillaume Brachet

guillaume.brachet@univ-tours.fr

Nicolas Aubert

nicolas.aubert@etu.univ-tours.fr

Marie Brachet-Botineau

marie.brachet@etu.univ-tours.fr

Giulia Emi de Olivera Preto

giulia.preto@butantan.gov.br

Isabelle Benz-de Bretagne

isabelle.benz-debretagne@univ-tours.fr
Hervé Watier

watier@med.univ-tours.fr

Laboratoire d'Immunologie, CHRU de Tours, Tours, France

ERL CNRS 7001 LNOx, Université de Tours, Tours, France

Instituto Butantan, São Paulo, Brazil

4 Laboratoire de Biochimie, CHRU de Tours, Tours, France

5 UMR 1253, Université de Tours, Tours, France

6 EA 7501 GICC, Université de Tours, Tours, France 


\section{Background}

On June 28th 1914, in Sarajevo, Duke Francis Ferdinand is murdered by Gavrilo Princip. This attack dooms the world to a deadly war, which will cause tens of million military and civilian casualties and around 20 million deaths. Aside from bullets and bombs, wound infection was the first among death causes. The major infections were gas gangrene and tetanus, both caused by germs belonging to the Clostridium genus.

C. tetani was isolated and cultivated for the first time by S. Kitasato in 1889 [1]. The next year, Kitasato and von Behring published their findings about the transfer of immunity against diphtheria and tetanus through serum in animals [2], launching the era of serotherapy, although this concept was first described by French physiologists [3]. Whereas antidiphtheria serotherapy rapidly met the medical needs and spread worldwide, anti-tetanus serotherapy hardly found its place before World War I. Indeed, contrarily to diphtheria antiserum, tetanus antiserum (TAS) was relatively ineffective when used for curative purposes, i.e. after the beginning of symptoms, both in animal models and in humans $[4,5]$. As explained by Edmond Nocard (1850-1903) as early as in 1895 , the disease directly depends on the presence of the tetanus toxin in the central nervous system [6], where it can be neutralized only by direct injection of TAS locally [7, 8], a very unusual procedure in routine clinical practice! It was quickly suggested that TAS should be used preventively and systematically $[8,9]$, but surgeons were hardly convinced, due to its lack of efficacy once the symptoms were present. At the beginning of the conflict, the Parke and Davis's manual clearly sums up the situation: "Some clinicians deny that its results are curative, although there is abundant evidence that its timely administration does prevent tetanus" [10].

During WWI, with the omnipresence of mud, soldiers were particularly exposed to tetanus, either through deep wounds or through trench foot disease, and tetanus soon became a priority issue to deal with. Between August and October 1914, in German military hospitals of the 15th Army Corps, 1744 cases of tetanus were reported among the 27,677 wounded soldiers [11]. In the British army, tetanus incidence among the wounded soldiers was 32 per 1000 during the sole month of October 1914 [12]. Systemization of prophylactic TAS in 1914 drastically decreased the incidence of tetanus. On both sides of the frontline, the needs for TAS increased accordingly and shortfalls led to buying serum to neutral countries, such as the USA, notably to the benefit of Parke and Davis Laboratories. This biologics pioneer was the first laboratory to be granted a licence for TAS production [13]. Over 600 horses were bred and immunized in order to fulfil the demand [14]. The horses were immunized with increasing doses of virulent $C$. tetani culture bouillon every 8 days "until no reaction to the culture is manifested and the blood shows the highest number of immunity units obtainable from that individual animal" [15].
In the 1900s, maintaining the cold chain would have been a real challenge, especially on the battlefront. It was only in 1911 that the French TAS-producing laboratory "Institut Pasteur" finally installed their first gas refrigerator to store antidiphteric and antitetanic sera [16]. Thus, it is likely that in frontline medical advanced posts, drugs intended for use in the trenches were to be stored either at ambient temperature, or half-buried in the ground. Immunoglobulins are known for their high stability and resistance to proteolysis. The longest stability studies performed until now have shown that $\operatorname{IgG}$ could remain stable over 25 years when stored at $-25{ }^{\circ} \mathrm{C}$ [17]. In the light of this information, we opened and characterized the remnants of a centuryold tetanus antiserum from a private collection for which no information as to the storage conditions were available. Orthogonal in vitro and in vivo techniques were implemented to search for intact IgGs and neutralizing power against the tetanus toxin. This work gives information about stability of IgGs conserved in a lightfree, sealed glass vial stored at ambient temperature for over a hundred years.

\section{Methods}

\section{Serum}

A tetanus antiserum from Parke, Davis \& Co., batch number: 042415-A, was used. The vial was unsealed under sterile conditions in an isolator. The serum was extracted with a $19 \mathrm{G}$ needle, filtered successively with $2 \mu \mathrm{m}, 0.45 \mu \mathrm{m}$ and $0.2 \mu \mathrm{m}$ PES syringe filter tips and split in $1 \mathrm{~mL}$ aliquot. Aliquots used for SEC and serum protein electrophoresis were stored at $+4{ }^{\circ} \mathrm{C}$; the others were flash-frozen in liquid nitrogen and stored at $-80{ }^{\circ} \mathrm{C}$ for dry ice shipment towards in vivo experiments. A control serum from a living horse was kindly supplied by Daniel Guillaume, from the Institut National de la Recherche Agronomique, Nouzilly, France.

\section{Protein concentration measurement}

\section{Spectrophotometric measurement of protein concentration}

A Nanodrop 2000 apparatus (ThermoFisher Science) was used. Phosphate buffer saline was used as blank. A 2- $\mu \mathrm{L}$ sample was loaded onto the measurement cell. Both the measurement cell and arm were rinsed with distilled water and dried with a clean cotton wipe between each sample. Protein concentration measurement was performed using the "A280 protein" program. 


\section{Size exclusion chromatography}

SEC was performed on an Alliance e2695 (Waters) equipped with a Wyatt miniDawn Treos and Optilab T-rEx (Wyatt Technology Europe GmbH). An AGILENT BIOSEC3 column $(300 \mathrm{~mm} \times 7.8 \mathrm{~mm}, 3 \mu \mathrm{m}$ particles, $300 \AA$ pores $)$ was used. A total of $100 \mu \mathrm{g}$ of each sample was injected onto the column and separated at a flow rate of $1 \mathrm{~mL} / \mathrm{min}$. The elution buffer was PBS pH 7.2. UV detection was performed at $280 \mathrm{~nm}$, with the PDA 2998 apparatus (Waters), whereas MALLS detection was performed with a three-angle (43.6 $6^{\circ}$; $90.0^{\circ} ; 136.4^{\circ}$ ) miniDawn Treos detector (Wyatt Technology Europe) operating with a $60 \mathrm{~mW}$ solid-state $658 \mathrm{~nm}$ laser. The molecular weights corresponding to the antibody peaks were calculated with Astra software version 6.0.6 (Wyatt Technology Europe). A differential index of refraction or $\mathrm{dn} /$ dc of $0.185(\mathrm{~mL} / \mathrm{g})$ and a second virial coefficient of 0 were used. Molecular weights were calculated with the Zimm equation. Bovine albumin and commercial trastuzumab were used as controls for albumin and $\mathrm{IgG}$, respectively.

\section{Serum protein electrophoresis}

Capillary zone electrophoresis was performed on a Capillarys $2 ®$ system (Sebia, France). After injection of $40 \mu \mathrm{L}$ of serum in the anode, protein separation was performed by applying a voltage of $9 \mathrm{kV}$ for $2.5 \mathrm{~min}$ in fused-silica capillaries filled with a $\mathrm{pH} 10$ borate buffer at $35.5^{\circ} \mathrm{C}$. Proteins were detected by measuring UV absorbance at $200 \mathrm{~nm}$ at the cathode capillary end. All reagents were provided by Sebia in a commercial kit including buffer solution, wash solution, sample diluent and plastic consumables. Data analysis was performed with the software package Phoresis (Sebia, France).

Peak areas defined by Capillarys $2 \AA$ system were converted to grams per litre by using the total protein value, which was measured on a Cobas c6000® analyser (Roche, France) through a Biuret method.

\section{In vivo measurement of the neutralizing capacity towards tetanus toxin}

The animals come from the Central Bioterium of the Butantan Institute, approved by the Ethical Committee for the Use of Animals of the Butantan Institute, protocol 1477/13. The national guidelines used in this research are the National Council of Animal Experimentation - CONCEA. For this assay, five different dilutions were made for the reference tetanus antitoxin and 5 different dilutions for the test sample using a dilution factor of 1.2. Each dilution contained a variable volume of reference antitoxin or test sample, a fixed volume of tetanus toxin and the required amount of saline solution with $1 \%$ peptone to make up a total volume of $2.4 \mathrm{~mL}$. These dilutions were incubated in an oven set at $37{ }^{\circ} \mathrm{C}$ for $1 \mathrm{~h}$. After the incubation period, $0.5 \mathrm{~mL}$ of each dilution were inoculated into 10 albino mice (Mus musculus) of the Swiss Webster line, of both sexes and weighing between 17 and $22 \mathrm{~g}$, totalizing 100 mice. The mice were monitored for $96 \mathrm{~h}$, in which the live/inoculated numbers were recorded and the serum neutralization activity was then calculated through a statistical program. At the end of assays, the animals were euthanized with an anaesthetic overdose of ketamine hydrochloride $(300 \mathrm{mg} / \mathrm{kg}$ ) and xylazine hydrochloride
Fig. 1 Photography of the vial and packaging of the tetanus antiserum

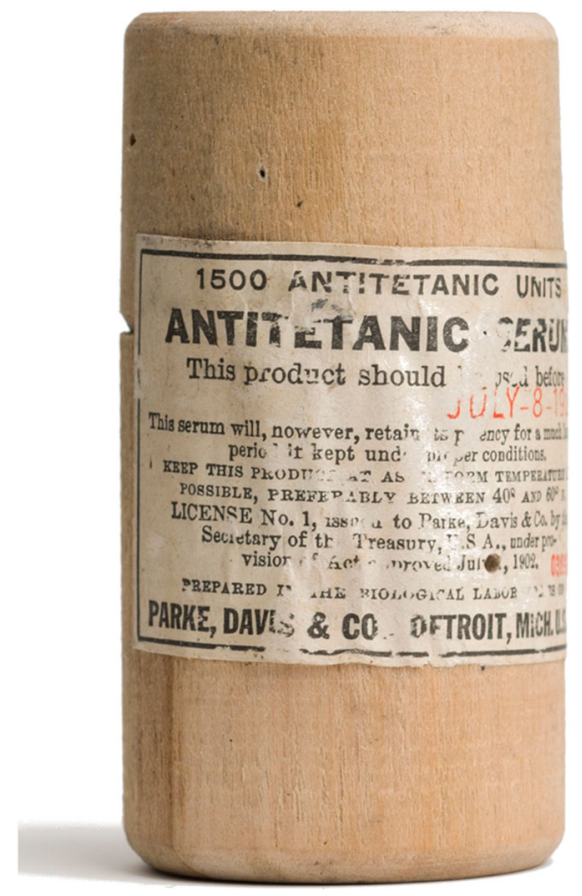


Table 1 Tetanus antiserum wooden packaging label text

1- 1500 Antitetanic units
2- Antitetanic serum
3- This product should be used before
4- July 8,1920
5- This serum will, however, retain its potency for a much longer
6- period if kept under proper conditions.
7- KEEP THIS PRODUCT AT AS UNIFORM TEMPERATURE AS
8- POSSIBLE, PREFERABLY BETWEEN $40^{\circ}$ AND $60^{\circ}$ F.
9- LICENCE No.1, issued to Parke, Davis \& Co. by the
10- Secretary of the Treasury, USA, under pro-
11- vision of Act approved July 1.1902
12- 042415-A
13- PREPARED IN THE BIOLOGICAL LABORATORIES OF
14- PARKE, DAVIS \& CO., DETROIT, MICH. U.S.A.

LINE 12, CORRESPONDING TO THE BATCH NUMBER, WAS WRITTEN IN RED

(30 mg/kg) administered intraperitoneally. This is a standard procedure for tetanus antiserum.

\section{Results}

\section{Description of the vial and packaging}

The vial was contained in a cylindrical wooden box (Fig. 1). The serum was contained in a small amber glass vial closed with a rubber septum, which was sealed with a material which could be aged wax, or paraffin. The slightly damaged label contained 14 lines of black and red ink text, according to which the serum contained 1500 antitetanic units and was prepared in the "Biological Laboratories of PARKE, DAVIS \& CO., DETROIT, MICH.U.S.A.”. Expiry date of the batch was July 8th, 1920, with possibility to use for a longer period "if kept under proper conditions" (cf. label), i.e. uniform temperature, between 4 and $15^{\circ} \mathrm{C}$. The full label text is available in Table 1. Interestingly, there was no mention of the manufacturing date either on the primary packaging or on the wooden box itself, and our attempts to find records containing the track of the batch number failed. However, since the TAS was found in France and was presumably imported by the US Army, we assume that it was manufactured either in 1917 or in 1918 .

\section{Analysis by size exclusion chromatography (SEC)}

The historical sample was injected onto the HPLC system, along with three controls: bovine serum albumin, rituximab, a monoclonal $\operatorname{IgG} 1 \kappa$, and equine serum from a living horse. The WWI TAS chromatogram contained two broad, badly resolved peaks around 7.5 and $8.5 \mathrm{~min}$ and several minor peaks. This hampered our attempts to calculate the estimated molecular weights of the major peaks by multi-angle laser light scattering coupled to refractometry (MALLS-Rf). Bovine serum albumin chromatogram is composed of 2 main peaks (Fig. 2), around 7.7 and 8.6 min corresponding to dimeric and monomeric forms, respectively, as confirmed by molar mass from MALLS-Rf (Supplementary Fig. 1). The control monomeric IgG peak was eluted around $7.8 \mathrm{~min}$. The control equine serum chromatogram contained two main peaks eluted at 7.7 and $8.4 \mathrm{~min}$, respectively, and two minor peaks around 3.5 and $6 \mathrm{~min}$.

\section{Serum protein electrophoresis (SPE) and protein titration}

Total measured protein was similar between control equine serum and TAS, with mean measurements of $70 \mathrm{~g} / \mathrm{L}$ and $75 \mathrm{~g} / \mathrm{L}$, respectively. SPE profile of the control equine serum contained $52.8 \%$ of albumin, vs. $49.5 \%$ in the TAS. Gammaglobulin repartition showed important discrepancies, and was hardly interpretable due to abnormal migration profiles (Fig. 3). In the control serum, gamma globulins accounted for $22.6 \%$ of total plasma proteins versus $1.6 \%$ in TAS, which corresponds to $1.2 \mathrm{~g} / \mathrm{L}$. Of note, this calculation was
Fig. 2 Size exclusion chromatography analysis of albumin (black), monoclonal IgG (grey), control equine serum (blue) and WWI tetanus antiserum (red). The latter contains several shouldered peaks could not be further analysed, but might correspond to immunoglobulins, fragmentation products and other low molecular weight species

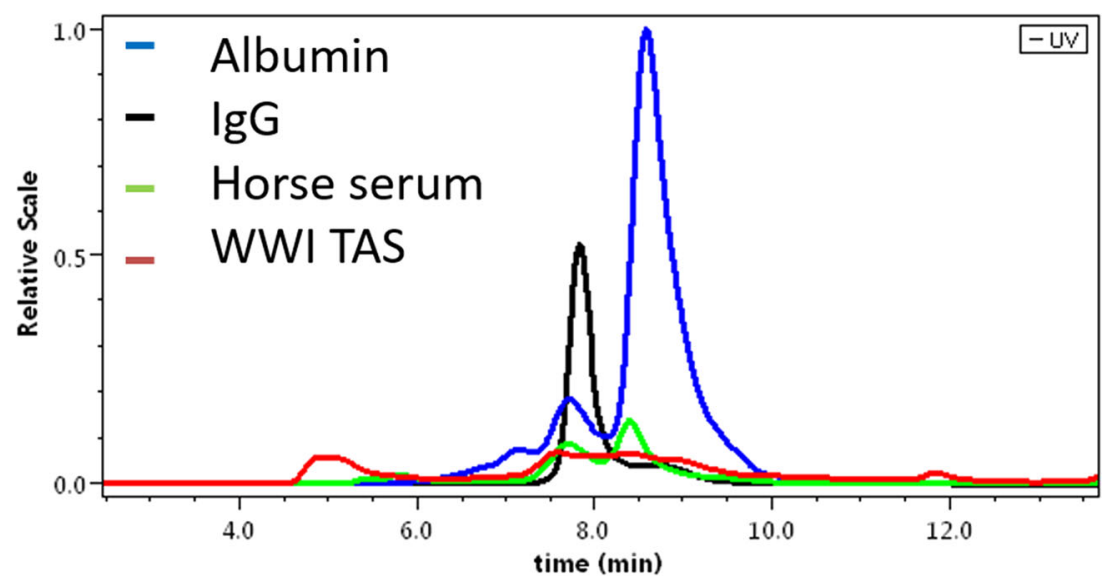


Fig. 3 Serum protein electrophoresis profiles from control equine serum a and WWI tetanus antiserum $\mathbf{b}$. Percentage and concentration of proteins for each peak are indicated below graph

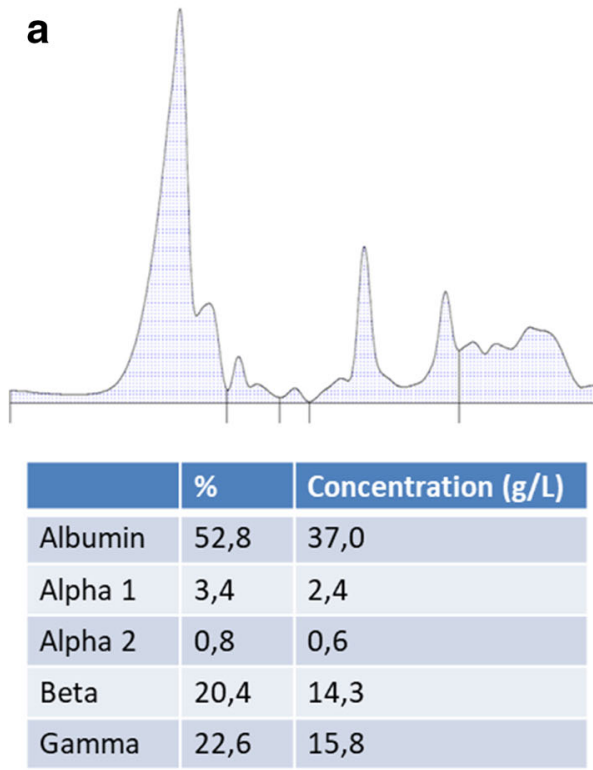

performed on the peaks which seemed to match best with their counterparts in freshly isolated serum.

\section{In vivo evaluation of the antitetanic serum activity}

All animals were healthy and test naïve before the experiment. Disappointingly, no difference of protection against tetanus was observed between treated vs. control mice regardless of the dilution of TAS (data not shown).

\section{Discussion}

In this work, we performed an in-depth physicochemical and biological characterization of a century-old horse TAS to determine whether some IgG persisted and could have preserved any activity against the toxin at ambient temperature in their original packaging. To our knowledge, this is the first study on an antiserum this old. We first searched for the presence of immunoglobulins in the serum. SEC and SPE analyses showed similarities between contemporaneous control and WWI TAS. Interpretation of the peaks in both techniques was hampered by the abnormal aspect of both the chromatograms and electrophoregrams. Immunoglobulin degradation is known to occur, through non-enzymatic processes such as deamidation of asparagine residues or fragmentation and aggregation [18]. This phenomenon is generally limited, but has never been analysed on such extensive periods. Despite this, persistence of immunoglobulins could not be ruled out in both techniques.

Even though the presence of $\mathrm{IgGs}$ at that stage was only hypothetical, we evaluated the neutralization capacity of the TAS, hoping to detect a weak titre.
Unfortunately, in vivo assays were unable to detect any residual activity meaning that the serum did not retain any neutralizing power towards the tetanus toxin, probably due to physicochemical instability such as aggregation, cleavage and conformational changes such as partial unfolding.

\section{Conclusion}

IgGs are well known for their resistance to proteolysis and their high stability. However, 100 years of conservation in suboptimal conditions overwhelmed this stability. As mentioned on the original packaging, the antiserum might be able to keep its potency after the expiry date if stored in appropriate conditions, without further details as to how long. It seems that 100 years is too much time or that the storage conditions were not appropriate.

Acknowledgements The authors wish to thank Pr. Philippe Billiald for his kind help, Daniel Bourry for the photography and studio work and Dr. Daniel Guillaume for kindly providing the control sample.

Authors' contributions Conceptualization, HW, MBB and GB; methodology, NA, MBB, GEOP, IBB, HW and GB; formal analysis, NA, GEOP, IBB, GB; resources, GB; writing - original draft preparation, NA, MBB, GEOP, $\mathrm{IBB}$, HW and GB; visualization, NA, MBB, GEOP, IBB, HW and GB; supervision, G.B.; project administration, GB; funding acquisition, HW.

Funding This publication was funded with support from the French National Research Agency under the program "Investissements d'avenir" Grant Agreement LabEx MAbImprove: ANR 10 LABX 53. The French National Research Agency is a public funding program, and does not take part in the design, data collection, analysis, interpretation or manuscript writing of the funded projects. 
Availability of data and materials All data available upon request to the corresponding author.

\section{Compliance with ethical standards}

Conflict of interest The authors declare that they have no conflict of interest.

Ethics approval and consent to participate The animals come from the Central Bioterium of the Butantan Institute, approved by the Ethical Committee for the Use of Animals of the Butantan Institute, protocol 1477/13. The national guidelines used in this research are the National Council of Animal Experimentation - CONCEA.

Consent for publication All authors gave their consent for the publication of the present version of the manuscript.

Abbreviations SEC, Size exclusion chromatography; SPE, Serum protein electrophoresis; MALLS, Multi-angle laser light scattering; Rf, Refractometry; TAS, Tetanus antiserum

Open Access This article is licensed under a Creative Commons Attribution 4.0 International License, which permits use, sharing, adaptation, distribution and reproduction in any medium or format, as long as you give appropriate credit to the original author(s) and the source, provide a link to the Creative Commons licence, and indicate if changes were made. The images or other third party material in this article are included in the article's Creative Commons licence, unless indicated otherwise in a credit line to the material. If material is not included in the article's Creative Commons licence and your intended use is not permitted by statutory regulation or exceeds the permitted use, you will need to obtain permission directly from the copyright holder. To view a copy of this licence, visit http://creativecommons.org/licenses/by/4.0/.

\section{References}

1. Kitasato S. Ueber den Tetanusbacillus. Z Hyg. 1889;7:225-34.

2. Behring E von. Ueber das Zustandekommen der DiphtherieImmunität und der Tetanus-Immunität bei Thieren; 1890 .
3. Lahaie Y-M, Watier H. Contribution of physiologists to the identification of the humoral component of immunity in the 19th century. mAbs. 2017;9:774-80.

4. Burton-Fanning FW. Antitoxin treatment of tetanus. Br Med J. 1894.

5. Hewlett RT. Tetanus antitoxin; its preparation and properties. $\mathrm{Br}$ Med J. 1895;1:464-5.

6. Nocard E. Sur la sérothérapie du tétanos. Essais de traitement préventif. Bull Acad Méd. 1895;xxxiv:407-18.

7. Roux E, Borrel A. Tétanos cérébral et immunité contre le tétanos. Ann Inst Pasteur. 1898;4:225-39.

8. Semple D. The treatment of tetanus by the intracerebral injection of antitoxin: with particulars of a case treated by this method, Followed by Recovery. Br Med J. 1899;1:10-2.

9. Struthers JW. The treatment of tetanus. Edinb Med J. 1908;1:21822.

10. Parke, Davis \& Company. A manual of biological therapeutics; sera, bacterins, phylacogens, tuberculins, glandular extracts, toxins, cultures, antigens, etc. Detroit: Press of Parke, Davis \& Company; 1914. https://catalog.hathitrust.org/Record/001582231

11. Wever PC, van Bergen L. Prevention of tetanus during the First World War. Med Humanit. 2012;38:78-82.

12. Bruce $\mathrm{D}$. Note on the incidence of tetanus among wounded soldiers. Br Med J. 1917;1:118-9.

13. Weekly Reports for July 10, 1914. Public Health Rep. 1914;180983.

14. Hoefle ML. The early history of Parke-Davis and Company. Bull Hist Chem. 2000;25:28.

15. Mohler JR, Eichhorn A. The need of controlling and standardizing the manufacture of veterinary tetanus antitoxin. Washington, D.C.: United States Department of Agriculture; 1909.

16. Gachelin G. La naissance des biotechnologies pharmaceutiques en France (1887-1914): Le sérum antidiphtérique de l'Institut Pasteur. Paris: Presses Universitaires de France; 2013.

17. Gislefoss RE, Grimsrud TK, Mørkrid L. Stability of selected serum proteins after long-term storage in the Janus Serum Bank. Clin Chem Lab Med. 2009;47. https://doi.org/10.1515/CCLM.2009. 121.

18. Correia IR. Stability of IgG isotypes in serum. mAbs. 2010;2:22132.

Publisher's note Springer Nature remains neutral with regard to jurisdictional claims in published maps and institutional affiliations. 